\title{
Analysis on Controlled Elements of Commercial Exhibition Space Design
}

\author{
Jie-fang JIN \\ Faculty of Art and Design, Shanghai Business School \\ Qi-zhao WANG \\ School of Art Design, Shanghai University of Engineering Science
}

\begin{abstract}
This paper analyzes the controlled elements of commercial exhibition space design and explores the influence of psychological and behavioral traits of consumers on these controlled designed elements from a perspective of space design. This paper puts emphasis on four key elements that influence commercial exhibition space, namely, spatial forms, texture, colors, and props.
\end{abstract}

KEYWORD: commercial exhibition space design; controlled elements; analysis

A commercial exhibition space is a space for communication between people and commodities and a home to commodities. The design of a commercial exhibition space should first satisfy human beings' need for space. It should also suit the consumption psychology of its audiences. Only in this way can the consumers be fully informed of the commodities and thus a bilateral interaction of propagation and acception of commodity information is achieved. As a result, the consumption process from commodity exhibition to commodity purchase is finished.

How can we efficiently propagate and accept the design of commercial exhibition space with commercial information? This requires the commercial exhibition designers to possess capability of planning and designing commercial space. In addition, the designers should have a good command of the language of commercial space design and use the language of controlled elements of commercial space design based on consumer psychology. Only in this way can designers design a reasonable commercial space and promote consumption.

The controlled elements of the design of a commercial exhibition space can extract, process, summarize, and transform typical materials on the basis of the conception of commercial exhibition space design. In addition, material methods like form, light, color, and texture can be applied to consider the visual effects of the entire commercial exhibition space. By adequate design and artistic manifestation, the consumers may have a series of chain reactions in image, psychology, and feeling

Shanghai City Art Science Planning Project 2015F23 when being exposed to the space. Therefore, a commercial exhibition space with artistic conception, geographical traits, and the spirit of the times is created. The controlled elements of the design of a commercial exhibition space include spatial forms, colors, texture, and props. So a designer can set about creation by using typical materials relevant to these controlled elements.

\section{CONTROLLED ELEMENTS OF COMMERCIAL EXHIBITION SPACE DESIGN----SPATIAL FORMS}

\subsection{Forms of a commercial exhibition space}

A commercial exhibition space is limited by the architecture of the space and has a certain spatial form. To realize the originality of a spatial form, a designer should first organize the spatial forms, that is reorganize the limited spatial forms to create the entire form of the commercial exhibition space. Generally, a commercial exhibition space limited by its architecture presents different geometrical shapes in two directions. One direction is the horizontal section, and the other is the vertical section. Rectangles, circles, and triangles are the most basic shapes among sectional forms. The dynamic combination of these three forms can create the entire form of a commercial exhibition space. If there is no special design concepts, it is advisable that the entire form of a commercial exhibition space be based on the original sectional forms limited by the architecture because the original sectional forms are ideally suitable to the structure and equipment of the architecture. However, using the original forms may diminish the aesthetic characteristics except 
that the original forms have outstanding characteristics. Using a different form should be cautious. Factors like the compatibility of the designed form with the structure and equipment and the ratio scale of the original form, and the influence of the designed form on the size should be taken into consideration. If designers deal with these factors properly, using a different form can create an extraordinary commercial exhibition space.

During the design of a commercial exhibition space, the visual effect of spatial components is distinct. So when an architectural component is exposed in the exhibition space, it should be used. With the development of architecture, industrialized and fabricated components tend to increase. These components are well designed by using exquisite techniques. So they can be used as decorations in a commercial exhibition space and need not be further decorated except that their proportion does not suit the atmosphere of the space. Additional components are mainly used for beautifying the image of a space and few are used for performing certain functions. So from the perspective of design, the aesthetic demand overtakes the functional demand in using additional components in order to satisfy the aesthetic demands of consumers. That is to say, using additional components can generally enhance the visual effect of a commercial exhibition space by pleasing the consumers.

\subsection{Organization form of a commercial exhibition space}

The design of commercial exhibition spaces is a major part of the design of modern commercial spaces. Space is a kind of substance like wood and stones. But space is formless by nature and its visual forms, light rays, dimensions completely depend on forms, which are identified by shapes. Certain geometrical shapes bring about certain psychological feelings, and certain spatial images correspond to certain life styles. So, to a certain extent, spatial forms have symbolic meanings. Spatial forms and the entire architectural form are reflected by the roof forms which are determined by the materials, proportion, and geometrical shapes of structural systems. Therefore, the controlled elements of the design of a commercial exhibition space can be handled like spatial form languages to induce the theme of a commercial exhibition space design and attract consumers by using the attributes of visual inertia of forms. For example, designers can adopt spatial forms like shapes, symbols, words, and figures to demonstrate the cultural connotation of commodities and unique characteristics and appeal of brands and create a particular atmosphere to combine the image of commodities with the image of the exhibition space, thus shaping, maintaining and improving the image of commodities and attract the interest of consumers to the commodities.

\section{CONTROLLED ELEMENTS OF COMMERCIAL EXHIBITION SPACE DESIGN----TEXTURE}

It is undeniable that human beings have a perception of texture. Since texture is an artistic form, fine texture can art up a commercial exhibition space in a most simplified way. Texture gives a visual feeling to achieve psychological association by its facial traits. Designers often combine the traits of texture with their design ideas to express a certain commercial exhibition space theme.

Texture may be smooth or coarse, soft or hard. Coarse texture includes stones, raw timber, coarse bricks, frosted glass, and pile fabric. Smooth texture includes glass, polished metal, ceram, silk, and organic glass. Even with the same texture, different materials bring different tactile sensation. For example, coarse stones are hard and heavy while pile fabric carpets are relatively soft and light. The latter texture feels better. Similarly, metal mirror surface and silk are both smooth, but the former texture is harder while the latter is softer.Pure wool fabrics feel both no matter they are smooth or coarse. But pure chaisel and heavy fabric feel uncomfortable although they are easy to maintain and low priced. Hard materials like bricks and stones, metals, and glass are endurable and wear-proof and hard to deform and have straight lines. In addition, they most hard materials are glossy, which can make a space look lively. But, they feel hard and cold. Designers can use these materials to create commercial exhibition space with different themes.

With the development of technology and emergence of various new architectural and decorative materials, designers should continuously identify and adopt these new materials to design a commercial exhibition space. The chosen materials, no matter they are bricks, stones, mud, wood, grass, vine, or bamboo, must adapt to specific nations and regions as different nations and regions have different geographical environments and economic conditions as well as different techniques. Using the local natural material and traditional techniques can not only reduce costs but also take advantage of the local techniques to make the consumers feel more intimate with the products compared with those stereotyped products. Designers can combine the traditional techniques and materials with modern ones to create a unique atmosphere. But the modern materials and techniques must suit specific environments and be integrated with the traditional materials and techniques. Only in this way can the design be lively and original. 
3 CONTROLLED ELEMENTS OF COMMERCIAL EXHIBITION SPACE DESIGN----COLORS

The colors of a commercial exhibition space should be determined by the theme of the space and the time when the space is designed. If the theme of a commercial exhibition space is historical, cold tone colors should be adopted to reflect the sense of history and dignity of traditional Chinese culture. If the theme of a commercial exhibition space is promotional, warm tone colors should be adopted to stimulate desire of consumers and promote transactions. Most commercial exhibition spaces use moderate colors to emphasize commodities and create a harmonious atmosphere. The time when the space is designed should also be considered. For example, in winter, warm tone colors are preferable so that consumers can have a sense of warm as the outdoors are already cold enough. Contrarily, cold tone colors are preferable in summer.

Colors on floors (including carpets) and ceilings combined with light can create a pleasant atmosphere. But different spaces with different functions should be handled separately. Generally, a commercial exhibition space use bright colors while the resting and negotiation areas may use moderate or light warm colors. Other areas may choose colors depending on their functions.

Colors can arouse keen feelings in a person and influence his/her emotions. Although a commercial exhibition space integrates other elements like forms and texture, colors are the element that can arouse a person's feeling and imagination better.

The colors of costumes and patterns of a region or nation are related with its temperament, lifestyle, production conditions, and local colors. The colors used by a region or nation originate from its customs and materials. These colors are the basis for designing a commercial exhibition space. The choice of colors vary with places and individuals. Some colors become a symbol of a place due to frequent use. The same color has different symbolic meanings in different regions and nations and has different emotional appeals. When designing a commercial exhibition space and drawing up the color plan, in order to create an aesthetic atmosphere, designers should not only satisfy general color design principles in various environments but also attempt to extract those symbolic colors by observing, learning, and recombining local abundant colors and select the main colors and match colors. By using local colors, the designers can rouse similar feelings and demonstrate the local style. In addition, designers should make full use of natural colors of various materials to create a humane and fashionable atmosphere.

\section{CONTROLLED ELEMENTS OF COMMERCIAL EXHIBITION SPACE DESIGN----PROPS}

Props refer to exhibition implements like stands, boards, shelves, and other implements used for exhibition. Designers should make various factors like models, proportions, dimensions, colors, compositions, and materials are compatible with each other so that the layout and form of a commercial exhibition space look reasonable

Showcases are generally used for protecting and highlighting important commodities. Showcases include those standing against walls, central showcases with glass on all sides, and showcases like desks with horizontal or slant glass shields, and setting boxes. Stands are another important implements used for bearing commodities, models, sand tables, and other decorations. Large stands can be composed of shelves or small standardized stands with various simple geometrical shapes, like square cylinders, cuboids, and cylinders. Generally, large commodities are displayed on lower stands while small commodities are displayed on higher stands. In a large commercial exhibition space, an extralarge stand can be designed for displaying a largescale commodities as the case may be.

One of the important traits of designing a modern commercial exhibition space is to demonstrate a static commercial space in a dynamic way. In this way, a commercial exhibition space may look lively and novel. A method of making a static space dynamic is to use mobile props. For example, rotating stands of various sizes can be used, especially for demonstrating large commodities like motors. The rotating stands enable the audiences to view the motors in various perspectives. Some audiences may have a test run on the stand. In modern commercial exhibition spaces, personal participation of audiences has become a trend especially in many famous commercial exhibition space fairs and exhibitions abroad because the participation of audience may have unexpected effects. As a result, mobile rotating stands have become a media between audiences and commodities. Some rotating stands are standardized, but most rotating stands are designed according to specific commodities.

The principles of designing and selecting props are as follows: firstly, designers should mainly use standardized and modular props except that the props need to be designed to meet special needs; secondly, designed should mainly use detachable props which are easy to combine, pack, transport and store; thirdly, the structures of props should be solid, reliable and easy to process; lastly, the props should have simple models and colors. The models, colors, specifications, and dimensions of props depend on the styles, dimensions, exhibitions nature, 
commodity traits, colors, and other factors of a commercial exhibition space. With the popularization of commercial exhibition space activities, more and more manufacturers research, design and produce new props for demonstrating commodities. Professional props tend to replace traditional props. Therefore, designers should first consider those standardized props with multiple functions rather than those props with special dimensions to reduce expenditure and facilitate layout.

During the design of a commercial exhibition space, different auxiliary facilities are used for different space objects. For example, there are specialized models and dress stands for clothes exhibition space and large-scale shelves and book racks for book exhibition space. The exhibition of other commodities also need specialized equipment. The equipment can be standardized or designed according to specific needs. Besides, props play an important role in expressing the theme and style of a commercial exhibition space. Therefore, designers can use or recombine typical props used by different regions and nations to express the theme and improve the appeal of a commercial exhibition space.

\section{ACKNOWLEDGEMENT}

This paper is one of the research results of the key business administration discipline research projects conducted by the Shanghai colleges and universities "Study on Layout Design of Commercial Exhibition Space"(No.NH1-2-1-1314).

\section{REFERENCES}

[1] Jin Jiefang, Wang Qizhao. Design of Exhibition Hall Space. Shanghai: Shanghai People's Publishing House, November, 2011.

[2] Li Yuegu. Commercial Exhibition Design. Heilongjiang Science Press, 2000.

[3] Peng Yigang. Architecture Space Combination Theory. Beijing: China Construction Engineering Press, 2001

[4] Zhang Lili, Ji Changhong, Yao Fengli. Consumer Psychology. Beijing: Peking University Press, February, 2010.

[5] Liu Yongde. Form Meaning Structure Combination. Tianjin: Tianjin Science and Technology Press, 2002

[6] Jiang Lin. Consumer Psychology and Behavior. Beijing: China Remin University Press, 2002. 